\title{
Diacritical Seismic Signatures for Complex Geological Structures: Case Studies from Shushan Basin (Egypt) and Arkoma Basin (USA)
}

\author{
Mohamed I. Abdel-Fattah ${ }^{1}$ and Hamed A. Alrefaee ${ }^{2}$ \\ ${ }^{1}$ Geology Department, Faculty of Science, Suez Canal University, Ismailia, Egypt \\ ${ }^{2}$ Geology Department, Faculty of Science, Kafr Elsheikh University, Kafr Elsheikh, Egypt \\ Correspondence should be addressed to Mohamed I. Abdel-Fattah; mabdelfattah99@gmail.com
}

Received 24 July 2014; Revised 8 October 2014; Accepted 8 October 2014; Published 2 December 2014

Academic Editor: Joerg Schleicher

Copyright (c) 2014 M. I. Abdel-Fattah and H. A. Alrefaee. This is an open access article distributed under the Creative Commons Attribution License, which permits unrestricted use, distribution, and reproduction in any medium, provided the original work is properly cited.

\begin{abstract}
Seismic reflection techniques show an imperative role in imaging complex geological structures and are becoming more acceptable as data interpreting tools in 2D/3D view. These subsurface geological structures provide complex seismic signature due to their geometrical behavior. Consequently, it is extremely difficult to interpret these seismic sections in terms of subsurface configuration. The main goal of this paper is to introduce seismic attributes as a powerful tool to interpret complex geological structures in different geological settings. In order to image these complex geological features, multiple seismic attributes such as coherence and curvature have been applied to the seismic data generated over the Shushan Basin (Egypt) and Arkoma Basin (USA). Each type of geological structure event usually generates a unique seismic "signature" that we can recognize and identify by using these seismic attributes. In Shushan Basin (Egypt), they provide a framework and constraint during the interpretation and can help prevent mistakes during a 3D structural modeling. In Arkoma Basin (USA), the seismic attributes results provide useful information for broader analyses of the complex structural relations in the region where the Ouachita orogenic belt intersects with the southern Oklahoma aulacogen. Finally, complex geological structures provide dramatically diacritical seismic signatures that can be easily interpreted by collaborating conventional seismic interpretation techniques with multiple seismic attributes.
\end{abstract}

\section{Introduction}

3D seismic data have become the key tool used in the oil and gas industry to understand the subsurface geology. This means mapping subsurface structure to find structures where oil and gas may be trapped or mapping faults that may be barriers to oil flow in a producing field. In addition to providing excellent structural images, the dense sampling of a 3D survey can sometimes make it possible to map reservoir quality and the distribution of oil and gas. The main aims of this study are to extract more fault information from seismic data by understanding and utilizing specific volumetric attributes (coherence and curvature) for enhancing structural interpretations from different case studies: the Shushan Basin (Egypt) and Arkoma Basin (USA). Although each of these seismic attributes is stand-alone tools and has produced wonderful and reliable results for decades to solve geological problems, integrating results from these different attributes with geological data adds an extra dimension towards solving geological problems.

Shushan Basin (Egypt), which represents one of the Mesozoic basins of the Western Desert, provides rewarding but difficult exploration opportunities. This is because of the complex structural history (Figure 1) and exploration has been almost exclusive for structural traps [1]. Delineating the detailed structural features affecting the Jurassic section using the available 3D seismic reflection data is extremely useful because they are responsible for the processes controlling the hydrocarbon traps in the basin. Faults and folds in Shushan Basin are very important controls on reservoir morphology and fluid movement. Identification of the fault types which occur in a particular reservoir is a vital step in defining 


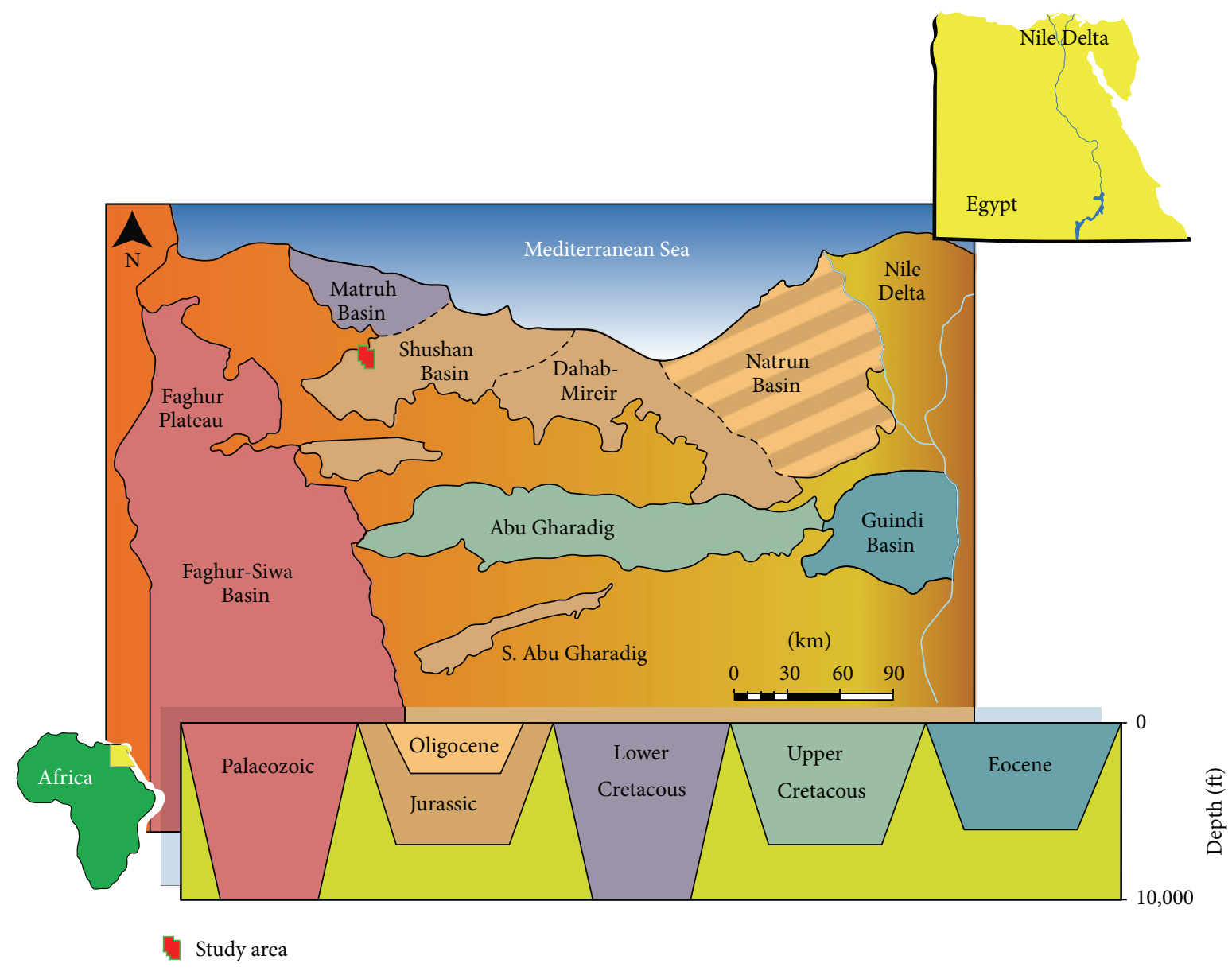

FIgURE 1: Location map of the Shushan Basin (Egypt).

reservoir geometry [2]. In Jurassic, several rift basins were formed as a result of the rifting process that was caused by the separation of North Africa/Arabia plate from European plate [1]. Three basins were formed during Jurassic time in the northern Western Desert [3]: Natrun Basin, the largest one, is located at the northeast and Matruh Basin with a north south trend was formed in the northwest. The north-south trend gives the Matruh Basin a possible northern marine connection with the Tethys during the Early Cretaceous. The third basin, Shushan Basin, was formed during Late Kimmeridgian to southwest of the Matruh Basin.

In Arkoma Basin (USA) (Figure 2), the processes responsible for the formation of faults and natural fractures in the sedimentary cover are mainly controlled by the Precambrian basement structures. Intrasedimentary features including collapse features, fractures, and faults in the Viola and Ellenberger carbonates are related to the underlying basement structures in the basin $[4,5]$. The main tectonic events dominating the continental United States in the Late Proterozoic and Phanerozoic were strongly influenced by the Precambrian basement structures [6]. Moreover, during the formation of the Rocky Mountains, the associated structures were extremely influenced by severe deformation alongside weakness zones in the basement. The importance of the basement structures arises also from hydrocarbon production from reservoirs in fractured basement [7]. Hydrocarbon accumulations may be found in the Lower Paleozoic strata in the Arkoma foreland basin buried underneath the thrust sheets of the Ouachita orogenic belt (Figure 2) [8].

\section{Study Area}

In Egypt, the study area is located in the north-western part of the Western Desert, about $50 \mathrm{~km}$ south of the Mediterranean coast, between latitudes $31^{\circ} 02^{\prime}$ and $31^{\circ} 12^{\prime} \mathrm{N}$ and longitudes $26^{\circ} 34^{\prime}$ and $26^{\circ} 45^{\prime} \mathrm{E}$, west of Qattara Depression. It covers about $455 \mathrm{~km}^{2}$ (Figure 1). The northern basins (Matruh, Shushan, Dahab-Mireir, and Natrun) initially formed as a single rift, perhaps during the Permo-Triassic, which developed into a pull-apart structure [9]. Marine conditions are first recorded in the Jurassic and Cretaceous sequences. Later tectonic events are presumed to have split the original basin into a series of smaller compartments.

In USA, the study area is located at the western part of Arkoma Basin in south Oklahoma and is bounded by the Arbuckle uplift to the southwest (Figure 2). The area 


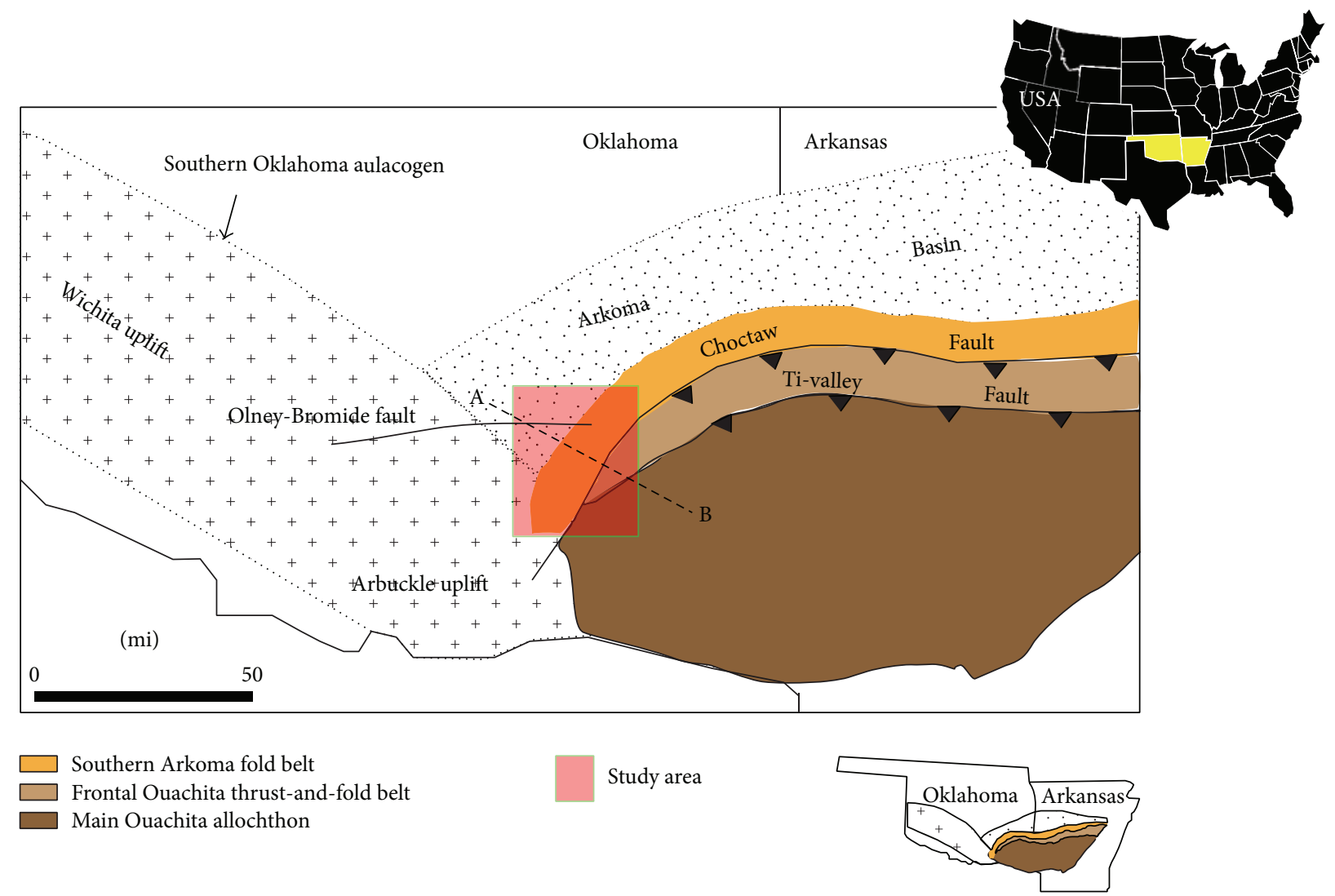

Figure 2: Location map of the Arkoma Basin (USA).

occupies part of the transition zone between Arkoma Basin and Ouachita orogenic belt. The leading thrust of the Ouachita orogenic belt, Choctaw fault, separates two different stratigraphic and structural styles. The deltaic strata of the Upper Atokan-Desmoinesian to the north of the fault are deformed by broad folds and fewer faults. The deep-water turbidites and shallow-water carbonates of Morrowan-Lower Atoka to the south of the fault are dominated by isoclinal folds and imbricate faults [10]. The boundaries of the 3D seismic survey provided for this study are shown as green rectangle (Figure 2).

\section{Geological Background}

In Egypt, the Mesozoic petroleum system is known to be active in the Western Desert region [11-14]. Mesozoic source rocks and reservoirs were deposited in the context of the Neo-Tethyan margins, with trapping in both Jurassic tilted fault blocks and Cretaceous inversion anticlines. These inversion anticlines were the result of the compressive Senonian event that inverted existing extensional grabens [15]. The basement tectonic map (Figure 3) clearly shows major faults crossing northern Egypt in an ENE-WSW direction with the upthrown blocks forming nonprospective ridges and the large downdropped blocks forming the petroleum basins of the Western Desert [2]. The North Western Desert was tectonically active during Jurassic and Cretaceous times [16]. In the Jurassic, several rift basins formed as a result of the rifting that was caused by the separation of North Africa/Arabia plate from European plate [1]. Following the rifting process, and during the Late Cretaceous, the Syrian Arc system developed due to NW to NNW-SE to SSE shortening that affected Egypt due to the close of Neotethys as a result of the convergence between African/Arabian and Eurasian plates. These forces led to the formation of folds of NE to ENE trend extending from Turkey through Egypt to NE Libya [2, 17-19]. The Syrian Arc folds were particularly documented in North Sinai and North Western Desert [20-24]. They are open, plunging folds with their axial trace trending NE-SW to ENEWSW. The North Western Desert structure is dominated by faults many of which can be identified from seismic and borehole data. Some of the normal faults suffered strike slip movements during part of their history. Strike slip movements seem to have affected the orientation of many of the fold axes. The strike slip movements were probably related to the lateral movements which the African plate underwent during the Jurassic (Sinistral) and Late Cretaceous (Dextral) [16].

In USA, the Ouachita orogenic belt is divided into three provinces depending on their structural styles [25] (Figure 2 ). These structural provinces include southern Arkoma Basin fold belt, frontal Ouachita thrust-and-fold belt, and the Ouachita allochthon. The study area lies at the transition zone between the Arkoma Basin and the Ouachita orogenic belt and could also be associated with northwest trending faults 


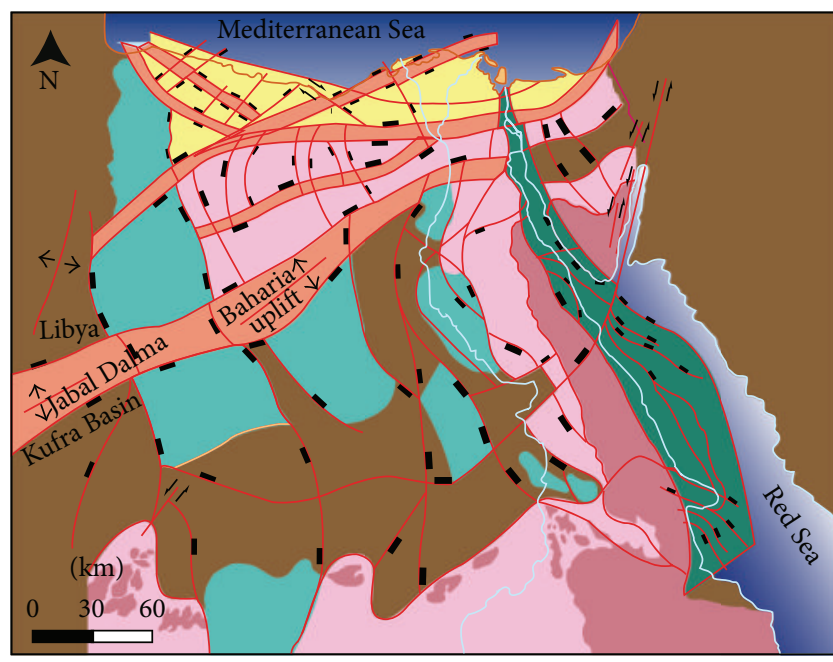

Figure 3: Basement structure map of Egypt (modified from [2]).

associated with the southern Oklahoma aulacogen [26, 27]. The central and northern parts of Arkoma Basin lie in the continental foreland province which has no compressional structures (Figure 4). Extensional faults due to the rifting of the southern margin of Laurentia during the Cambrian affected the basement and the Early Paleozoic sedimentary cover [28]. During the Early Atokan-Desmoinesian, an energetic stage of faulting dominated the platform rocks synchronously with the downwarping of the basin flank. The deposition of the Atoka Formation was associated with active, NE-SW striking faults that have downthrows to the south. As a result, the basin subsidence and accumulation rates of sediments accelerated [25].

\section{Methodology}

Seismic attributes are defined as specific quantities of geometric, kinematic, dynamic, or statistical features derived from seismic data [29]. In 2004, there were over 220 reported seismic attributes and there are even more today. A valuable seismic attribute is one that enhances geologic features including structural features like faults, folds, or depositional and stratigraphic elements such as channels and lobes [30]. It is important to select seismic attributes that will be most useful in exhibiting the features of interest in a specific seismic dataset. For this reason, one must be familiar with all aspects of the data (i.e., dip, azimuth, and acquisition parameters) and geologic setting, in order to select the attributes that are likely to work best. Perhaps the most widely used attribute is coherence because of its fault detection ability [31]. Another widely used attribute is curvature, which is a recent addition to the seismic attributes world. Curvature focuses on characterizing structural geometry [32].

Coherence attribute is an edge detection attribute that highlights geologic features that have abrupt boundaries. Due to its ability to image discontinuities, coherence is applicable to many types of structural and stratigraphic events. Bahorich and Farmer (1995) described the coherence seismic attribute as a measure and representation of the trace-to-trace similarities of seismic reflections [33]. Depending on a trace's neighboring waveform and amplitude likeness in the in-line or cross-line directions, the algorithm attempts to predict a center trace value using an $\mathrm{N}$-trace operator. If the central trace value is predictable, the area is coherent and a low value is output, where the area is incoherent or the central trace value is not predictable, a high value is inserted. The result is a dataset where nonpredictable values are highlighted against a continuous background. Therefore, the display identifies faults, fractures, channels, and other sharp-edged stratigraphic features because of the lateral changes in seismic traces that occur at these discontinuities [34, 35]. Many studies demonstrate this attribute is capable of pinpointing faults, fractures, channels, and other types of geologic features [30, $31,33,34]$. For this reason, the use of coherence in this study examines the previous interpretations of complex geological structures in the Shushan Basin (Egypt) and Arkoma Basin (USA).

Coherence is a measure of the similarity between two datasets. The seismic coherence technique was first proposed by Bahorich and Farmer in 1995 [33] and in 1996 they applied for a patent entitled "signal processing and prospecting method," namely, first generation coherence, or $\mathrm{Cl}$ for short [36]. In the $\mathrm{Cl}$ algorithm, along in-line traces or cross-line traces, every time we take two traces data and then calculate the coherence of these data. Therefore, the $\mathrm{Cl}$ algorithm is the geometric mean of the coherent attributes of the secondorder statistics of two adjacent in-line traces and two adjacent cross-line traces, but its noise immunity is weak. The second generation coherence technology, or C2 for short, was first proposed in 1998 [35] and in 1999 [37] the third generation coherence algorithm, or C3 for short, was proposed [37]. The C3 method which was used in this study is the most accurate and robust among them [38]. The algorithm is described as follows. In 3D seismic data, data in a time window ( $j$ traces and $N$ samples) is taken to form a matrix $D$ :

$$
D=\left[\begin{array}{cccc}
d_{11} & d_{12} & \cdots & d_{1 J} \\
d_{21} & d_{22} & \cdots & d_{2 J} \\
\vdots & \vdots & \ddots & \vdots \\
d_{N 1} & d_{N 2} & \cdots & d_{N J}
\end{array}\right]
$$

Its covariance matrix is $E=D^{T} D$. So the coherence is calculated as

$$
C=\frac{\lambda_{1}}{\operatorname{Tr}(E)}
$$

where $\lambda_{1}$ is the maximum eigenvalue of matrix $E$ and $\operatorname{Tr}(E)$ is the trace of matrix $E$.

Curvature attribute is similar to the coherence attribute. It reveals many of the same geologic features, but it differs because it focuses on the geometric aspects of reflectors [31]. Stewart and Podolski in 1998 were of the first to apply curvature analysis to seismic surfaces computing local slopes and estimating 3D shape [39]. Where features occur, their presence is recorded in multiple seismic traces. By linking seismic reflections on these traces, a regional dip and azimuth is determined. The newly created dataset consists of values 
NW

SE

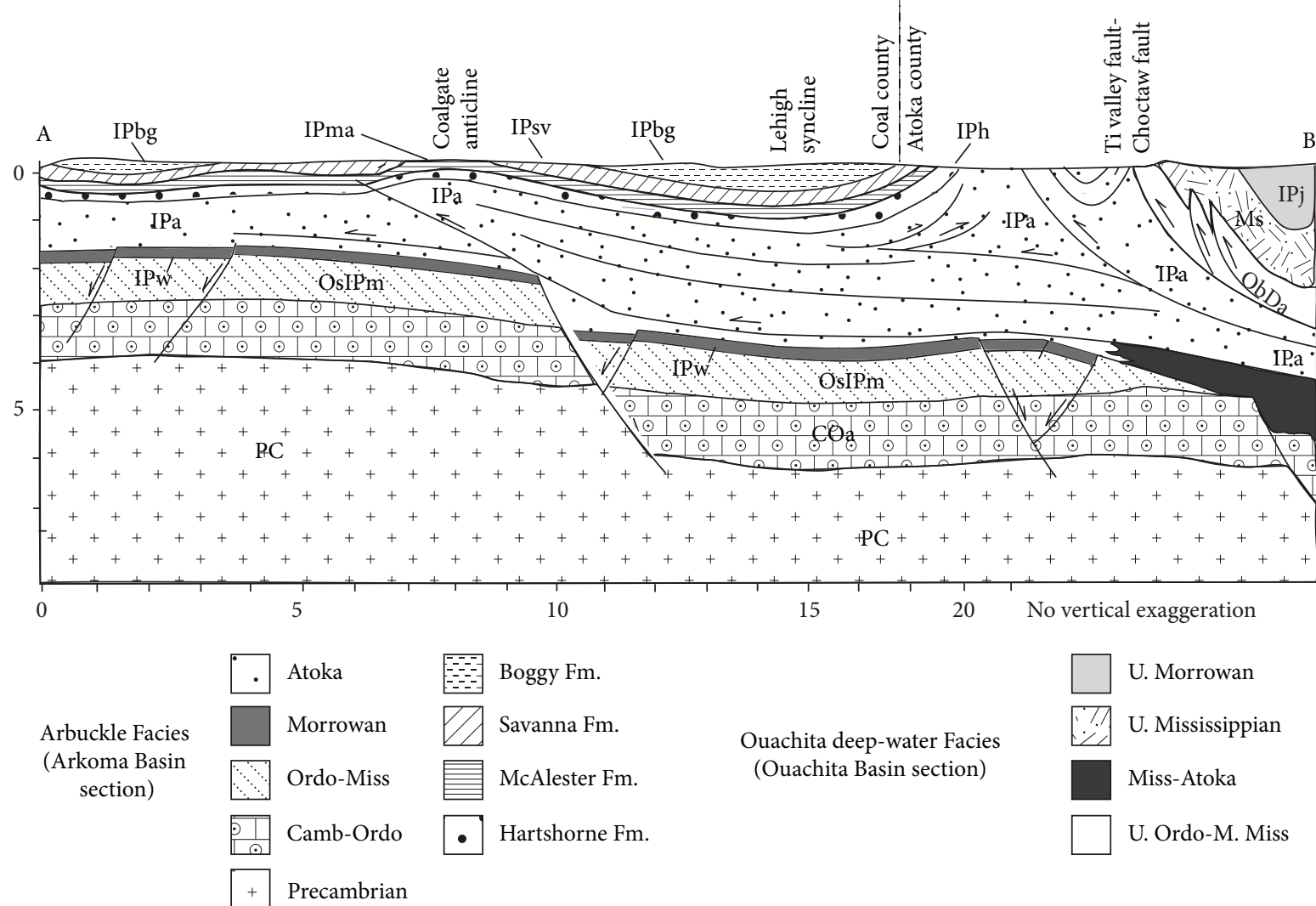

FIgURE 4: Structural cross section AB across Ouachita orogenic belt, modified from [25].

indicating to what degree certain areas deviate from being planar $[32,40]$. The result is a $3 \mathrm{D}$ attribute that highlights seismic reflections of zero, most-positive, and most-negative curvature. Because this attribute removes regional dip, it enables the emphasis of smaller-scale features like faults, fractures, flexures, and folds [40-42]. This study uses volume curvature to help identify complex geological structures in the studied basins.

Volume curvature attributes are computed much like horizon curvature attributes. Following the theory of horizon curvature attributes given by Roberts (2001) [40], curvature properties can be defined in terms of the coefficients of a second-order polynomial in $x$ and $y$ that locally approximates the reflection surface, $z(x, y)$ :

$$
z(x, y)=a x^{2}+b y^{2}+c x y+d x+e y+f
$$

Coefficient $f$ is the depth of the surface at the origin, $x=0$ and $y=0$. It can be ignored, as it has no influence on curvature. The other coefficients derive from first-order and second-order partial derivatives of the reflection surface $z$ with respect to $x$ and $y$. With $\rho_{x}$ being the reflection slope in the $x$ direction and $\rho_{y}$ being the reflection slope in the $y$ direction, these coefficients are listed as follows:

$$
a=\frac{1}{2} \frac{\partial^{2} z}{\partial x^{2}}=\frac{1}{2} \frac{\partial \rho_{x}}{\partial x}
$$

$$
\begin{aligned}
& b=\frac{1}{2} \frac{\partial^{2} z}{\partial y^{2}}=\frac{1}{2} \frac{\partial \rho_{y}}{\partial y} \\
& c=\frac{\partial^{2} z}{\partial x \partial y}=\frac{\partial \rho_{x}}{\partial y}=\frac{\partial \rho_{y}}{\partial x} \\
& d=\frac{\partial z}{\partial x}=\rho_{x} \\
& e=\frac{\partial z}{\partial y}=\rho_{y} .
\end{aligned}
$$

After obtaining the coefficients, we can easily calculate the curvatures, such as the most-positive or most-negative curvature, the mean curvature, the Gaussian curvature, the maximum and minimum curvature, and the dip curvature. The maximum curvature attribute is very effective at delimiting faults and fault geometries [40]. A fault on this attribute is represented by the juxtaposition of positive curvature values (red) and negative curvature values (blue). In addition, the curvature also defines the orientation of the faults, as positive curvature values represent the upthrown side and the negative values the downthrown side of the fault. The algorithm of the maximum curvature $\left(K_{\max }\right)$ is described as follows:

$$
K_{\max }=K_{m}+\sqrt{K_{m}^{2}-K_{g}}
$$




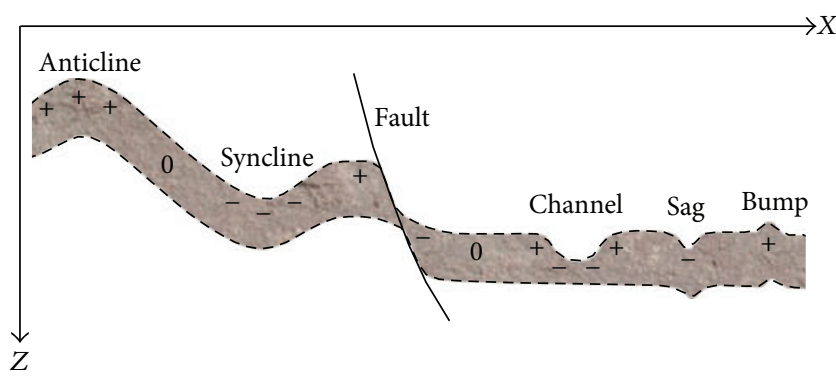

FIgURE 5: Sign convention for curvature attributes. Positive curvature reveals anticlines and reflection bumps; negative curvature reveals synclines and reflection sags.

where $K_{m}$ is Mean curvature and $K_{g}$ is Gaussian curvature [43]:

$$
\begin{aligned}
& K_{m}=\frac{a\left(1+e^{2}\right)-c d e+b\left(1+d^{2}\right)}{\left(1+d^{2}+e^{2}\right)^{3 / 2}}, \\
& K_{g}=\frac{4 a b-c^{2}}{\left(1+d^{2}+e^{2}\right)^{2}} .
\end{aligned}
$$

The most-positive curvatures (and the most-negative curvatures) are easily related to geologic structures and are most useful in delineating faults, fracture, flexures, and folds [41]. They can provide a more detailed and less ambiguous attribute for defining subtle lineaments related to regional or local stresses than the other curvature attributes [44]. The formulae of the most-positive curvature $\left(K_{\text {pos }}\right)$ and the mostnegative curvature $\left(K_{\text {neg }}\right)$ are listed as follows:

$$
\begin{aligned}
& K_{\text {pos }}=(a+b)+\sqrt{(a-b)^{2}+c^{2}}, \\
& K_{\text {neg }}=(a+b)-\sqrt{(a-b)^{2}+c^{2}} .
\end{aligned}
$$

Most-positive curvature records the most positive rate of change of the reflection dip and azimuth. It highlights "frowns" in seismic reflections, or reflection bumps. It is closely related to Most-negative curvature, which highlights "smiles" or reflection sags. Normal faults often exhibit positive curvature on the up-thrown side and negative curvature on the down-thrown side. The sign convention employed for curvature attributes is illustrated in Figure 5.

Volumetric curvature attributes computed from 3D seismic data are powerful tools in the prediction of fractures, faults, and other stratigraphic features [44, 45]. Initial curvature applications were limited to picked 3D seismic horizons. Horizon-based curvature is limited not only by the interpreter's ability to pick events, but also by the existence of horizons of interest at the appropriate level in 3D seismic data volumes. Horizon picking can be a challenging task in data sets contaminated with noise and where rock interfaces do not exhibit a consistent impedance contrast amenable to human interpretation [45]. To address this issue, AlDossary and Marfurt (2006) generated volumetric estimates of curvature from volumetric estimates of reflector dip and azimuth [41].

Corendering coherence and curvature volumes allow us to see the correlation of discontinuities with the corresponding seismic signatures. Many studies give the impression that curvature is superior to discontinuity for all purposes. However, for routine mapping of faults and channels, discontinuity is consistently more interpretable than curvature, whether derived from seismic data or their amplitudes [46]. Amplitude change is often better as well. Curvature reveals finer detail than other attributes, but the significance is unclear. Therefore, 3D volume rendering is one form of visualization that involves opacity control to view the features of interest "inside" the 3D volume [47]. A judicious choice of opacity applied to edge-sensitive attribute subvolumes, such as curvature or coherence, corendered with the seismic amplitude volume can both accelerate and lend confidence to the interpretation of complex structure and stratigraphy.

\section{3D Seismic Data and Seismic Attributes}

5.1. Shushan Basin (Egypt). The seismic data acquisition programmed for Badr Petroleum Company (BAPETCO) in the study area initially comprised a 3D seismic survey grid of $455 \mathrm{~km}^{2}$ of surface coverage with $400 \mathrm{~km}^{2}$ full-fold of the subsurface coverage. Because of the role faults often play in the entrapment of hydrocarbons in the Shushan Basin, the techniques for finding and mapping faults have considerable importance. The study area is highly faulted. The faults affecting the time zone of interest need to be interpreted to reveal the geologic history of the area and allow horizon picks, as well as to help in predicting what sort of hydrocarbon traps may be present in the area. Where discontinuities are well defined, the position of the fault trace may be highly evident on the record sections event to someone entirely inexperienced in seismic interpretation. All the interpreted faults through the seismic sections are extensional normal faults that generally form grabens and half grabens that extend throughout the study area (Figure 6). The length of these fault planes varies from more than 6 kilometers to minor faults with lengths of few hundreds of meters. Their vertical extensions (in the time axis) vary from approximately $200 \mathrm{~ms}$ to about $2500 \mathrm{~ms}$ for major faults. Figure 6 shows two systems of normal faults, one group dipping to the right and the other to the left. Throws are indicated quite clearly by the displacement of the more conspicuous reflections. The study area is controlled by NE-SW, NNW-SSE faults, which are being intersected and displaced by a major E-W transverse fault. Most of these faults are throwing to the northwest and southeast and make a pattern of grabens and horsts.

Seismic attributes (Figures 7 and 8) such as coherence and curvature that highlight discontinuities in the seismic data are useful for illuminating the complex geological structures in the study area. Figures 7(a) and 7(b) show amplitude and coherence attribute. Coherence attribute accentuates part of the amplitude volume where there are discontinuities in the amplitude field. These occur where there are faults and the horizon amplitudes are discontinuous due to rock deformation. Discontinuities also occur where channel boundaries 


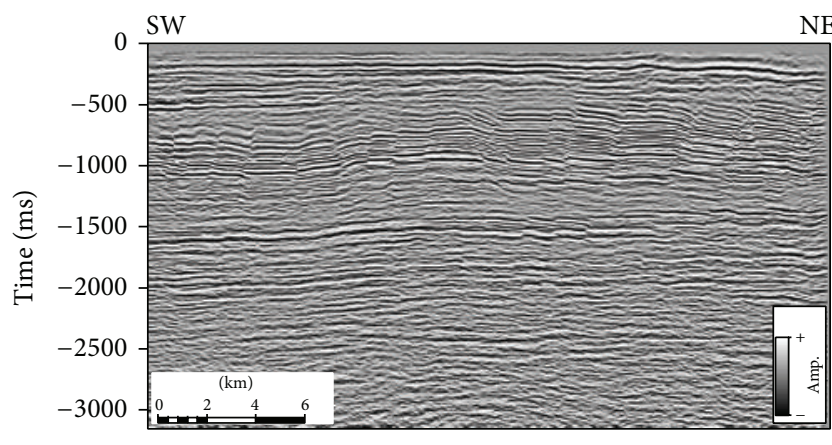

(a) Uninterpreted seismic line

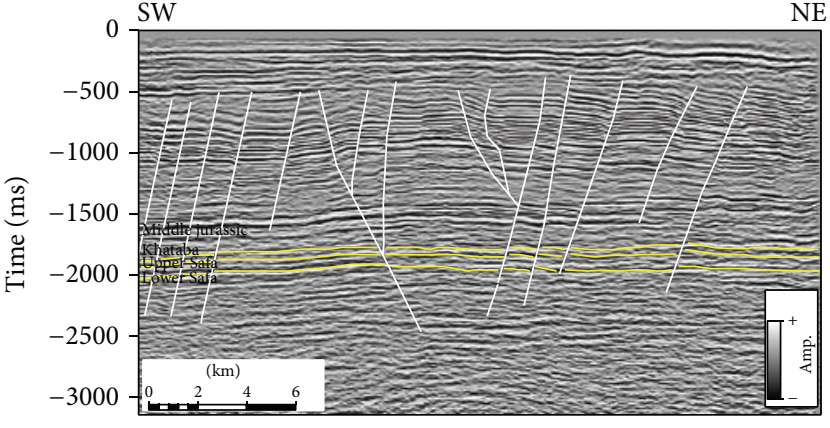

(b) Interpreted seismic line

FIGURE 6: (a) Uninterpreted seismic line and (b) interpreted seismic line in SW-SE direction showing a complex structural pattern in the Shushan Basin (Egypt).

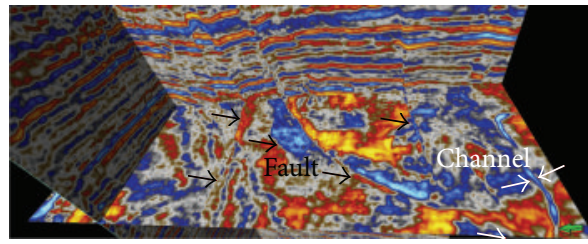

(a) Amplitude

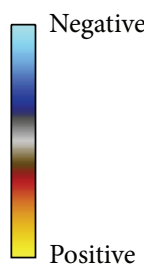

Positive

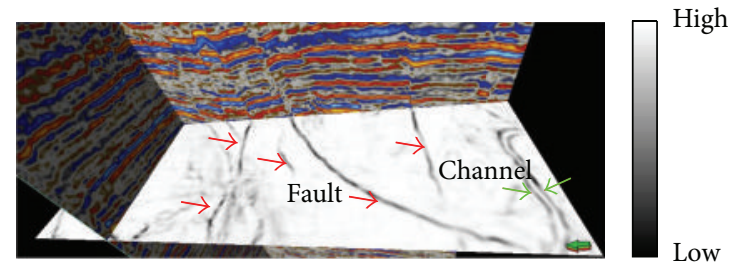

(b) Coherence

FIgURE 7: (a) Amplitude and (b) coherence attributes showing complex structure (faults and channel) in time slice $1950 \mathrm{ms.}$

interrupt horizons and these are also well imaged by coherence attribute. The coherence images clearly reveal faults and channel features (Figure 7(b)). Volumetric curvature attribute shows high values where horizons are bent rather than broken (Figure 8). Figures 8(a), 8(b), and 8(c) show maximum curvature $\left(K_{\max }\right)$, most-positive curvature $\left(K_{\text {pos }}\right)$, and most-negative curvature $\left(K_{\text {neg }}\right)$. Curvature attribute at discontinuities does not need yield predictable results, but typically horizons are bent prior to breaking at faults so curvature attribute may well pick out a fault. For example, curvature attribute calculated in the region of a low throw normal fault will show high positive curvature at the edge of the footwall coupled with high negative curvature at the edge of the hanging wall. This characteristic pair of high positive and negative curvatures can be used to interpret low throw faults. At channel boundaries, curvature may have high positive values at the levees and negative values in the thalweg. Not all channels result in negative curvature anomalies. The feature in Figures 8, 9, and 10 clearly appears to be a channel on the coherence image but appears as a positive curvature anomaly along the channel axis. This anomaly is due to differential compaction over a sand-filled channel incised in a shale matrix, resulting in a local high.

5.2. Arkoma Basin (USA). The 3D seismic survey is located at the westernmost part of Arkoma Basin, Oklahoma, and it was acquired primarily for imaging the Hunton Limestone and Woodford Shale (Figure 2). Initially, we interpreted the main faults to recognize the dominant structural styles, and we picked the tops of the basement, Timbered Hill Group,
Woodford Shale, and Caney Shale horizons. We generated volumetric attributes including coherence and curvatures.

The vertical seismic section $\mathrm{XX}^{\prime}$ shows reactivation of the normal faults as compressional ones (Figure 10). A principle rift (normal) fault (F1) may be reactivated as a high angle reverse fault due to the Late Paleozoic compressional tectonism. In Oklahoma, zones of weakness in the continental crust that developed during the Proterozoic were reactivated twice. These zones were reactivated during the Cambrian rift resulting in NW striking normal faults which were reactivated again as oblique strike slip faults during the Late Paleozoic time. A number of high angles thrust faults were recognized, dominating the older strata close to the Choctaw fault. In the Arbuckle uplift area, southwest of the study area, the Cambrian rift-related rhyolitic rocks are exposed in the hanging wall of the Washita Valley thrust fault, and the Ordovician carbonates are exposed in the footwall. Similarly, F2 represents a minor normal fault that was reactivated as a reverse one.

Figures 11, 12, and 13 show the power of the seismic attributes in enhancing and optimizing the seismic interpretation process. The time slice through the seismic amplitude shows a little clear image of the complex structural signature of the area of the intensive deformation (Figure 11(a)). On the other hand, the time slice through the coherence volume enhances the occurrence of the faults (low coherent trends) as dark lineaments and shows the highly deformed rocks as dark zones (Figure 11(b)). Note that there are no significant coherence anomalies for folds. The coherence is not able to distinguish the upthrows from the downthrows or anticlines 


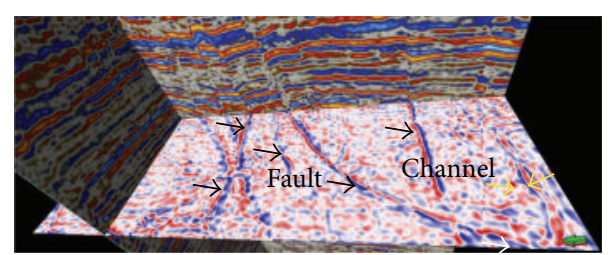

(a) $K_{\max }$

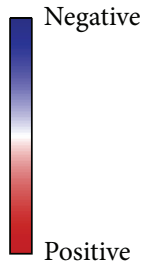

Positive

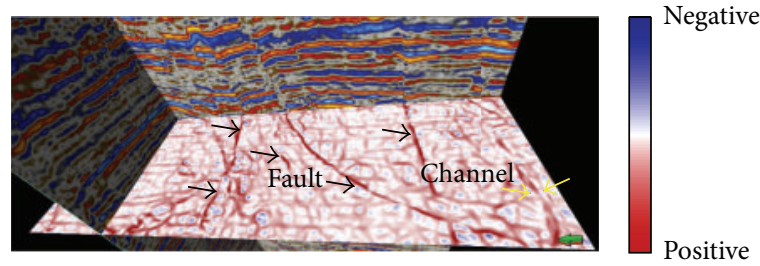

(b) $K_{\text {pos }}$

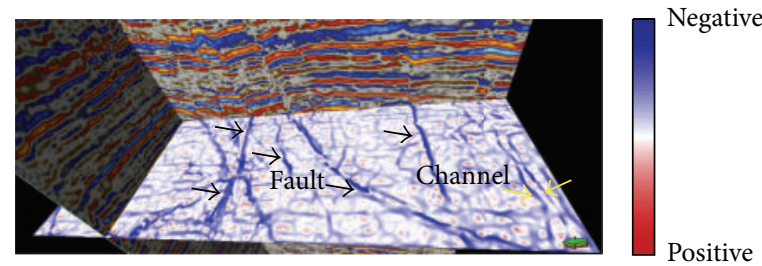

(c) $K_{\text {neg }}$

FiguRE 8: (a) Maximum curvature $\left(K_{\max }\right)$, (b) most-positive curvature $\left(K_{\text {pos }}\right)$, and (c) most-negative curvature $\left(K_{\text {neg }}\right)$ exhibiting faults and channel with differential compaction.

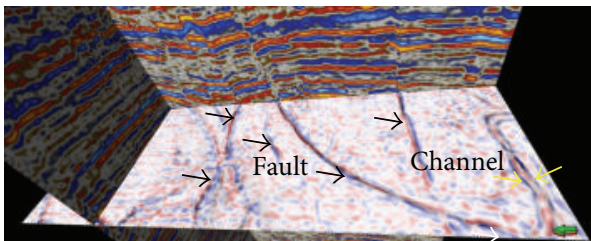

(a)

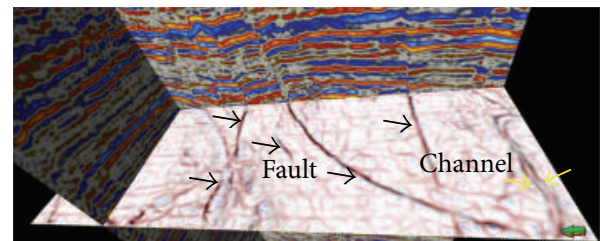

(b)

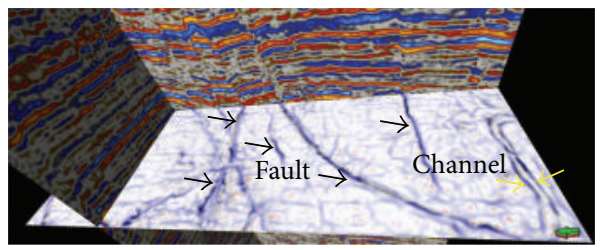

(c)

FiguRE 9: Corendering coherence (50\% opacity) with (a) maximum curvature $\left(K_{\max }\right)$, (b) most-positive curvature $\left(K_{\text {pos }}\right)$, and (c) mostnegative curvature $\left(K_{\text {neg }}\right)$ showing complex structure (faults and channel) in time slice $1950 \mathrm{~ms}$. Note that the correlation of channel edges seen on coherence obtained by corendering the three image.

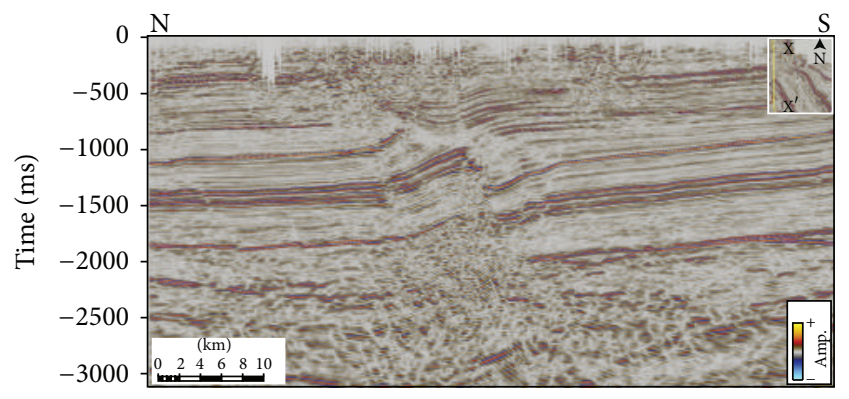

(a) Uninterpreted seismic line

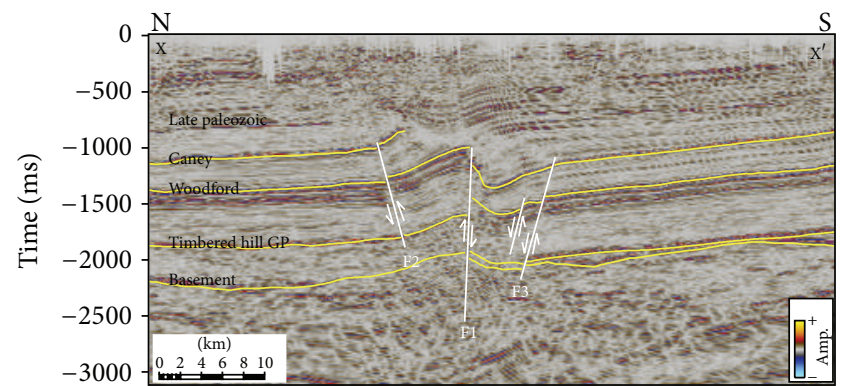

(b) Interpreted seismic line

Figure 10: (a) Uninterpreted seismic line $\mathrm{XX}^{\prime}$ and (b) interpreted seismic line $\mathrm{XX}^{\prime}$ showing an area of intensive deformation where some basement normal faults were reactivated as reverse faults (F1 and F2). 


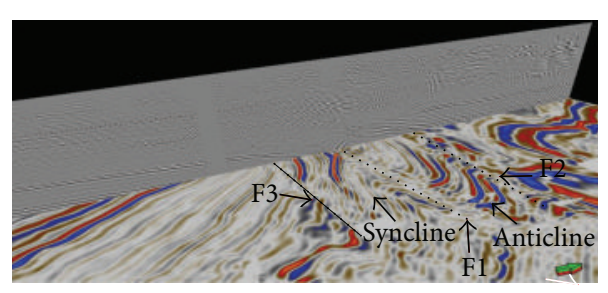

(a) Amplitude
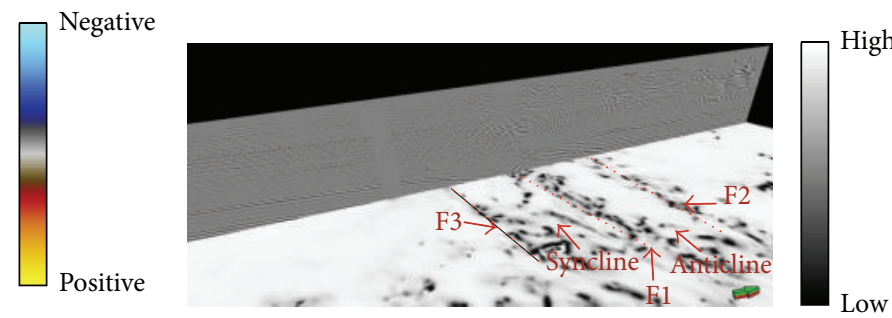

(b) Coherence

Figure 11: (a) Amplitude and (b) coherence attributes showing interpreted faults (F1, F2, and F3) and folds. Note that there are no significant coherence anomalies for folds.

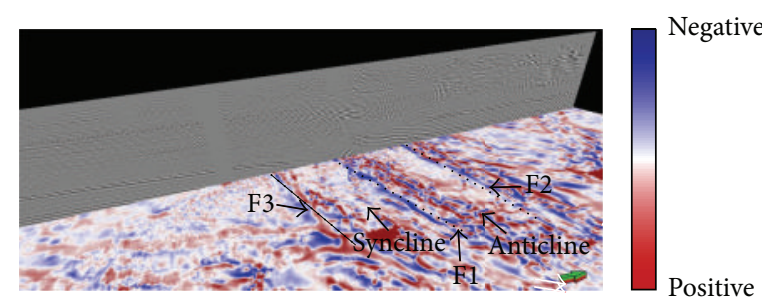

(a) $K_{\max }$

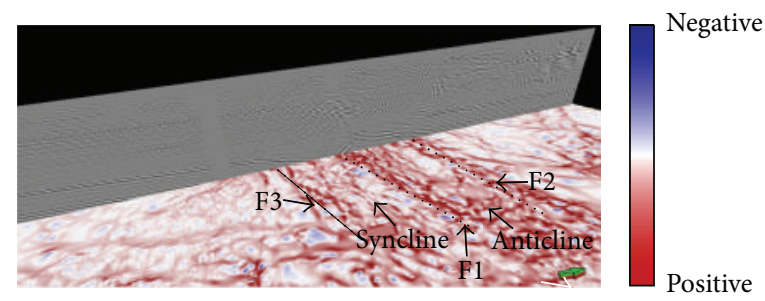

(b) $K_{\text {pos }}$

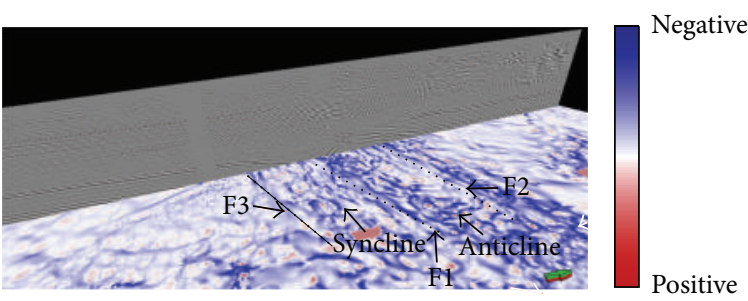

(c) $K_{\text {neg }}$

FiguRE 12: (a) Maximum curvature $\left(K_{\max }\right)$, (b) most-positive curvature $\left(K_{\text {pos }}\right)$, and (c) most-negative curvature $\left(K_{\text {neg }}\right)$ showing anticlinal and syncline feature. Minimum curvature features (blue) delineate the two limbs of the anticline fold, while maximum curvature (red) delineates the axial plane.

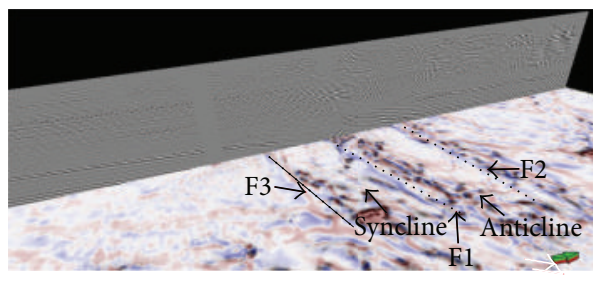

(a)

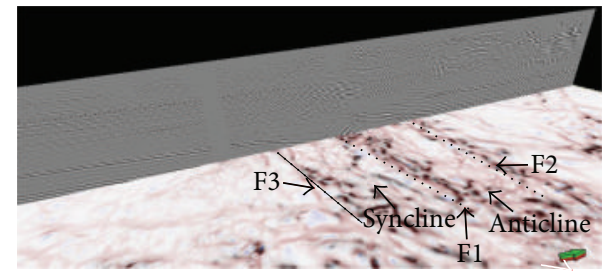

(b)

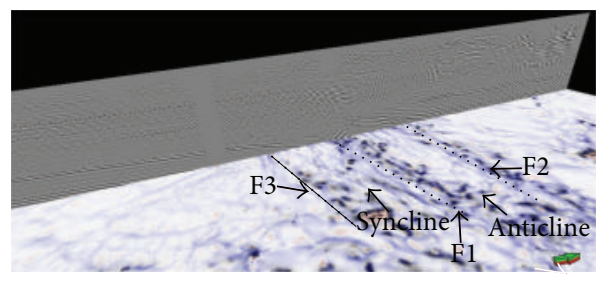

(c)

FIGURE 13: Interpreted faults (F1, F2, and F3) and folds delineated by corendering coherence (50\% opacity) with (a) maximum curvature $\left(K_{\max }\right)$, (b) most-positive curvature $\left(K_{\text {pos }}\right)$, and (c) most-negative curvature $\left(K_{\text {neg }}\right)$. 
from synclines while the curvature shows the anticlines and upthrows as red color and synclines and downthrows as blue color (Figure 12). Volumetric curvature attributes indicate a better focusing of the folds features as compared with amplitude and coherence. Figure 13 shows corendering coherence (50\% opacity) with (a) maximum curvature $\left(K_{\max }\right)$, (b) mostpositive curvature $\left(K_{\text {pos }}\right)$, and $(c)$ most-negative curvature $\left(K_{\text {neg }}\right)$, where the coherence (low values in black), mostpositive curvature (high values in red), and most-negative curvature (high negative values in blue) attributes are corendered with the seismic volume in a strat cube. Notice how, in one single composite display, it is possible to interpret the change in the waveform discontinuities (black), the upthrown edges of the fault blocks (red), and the downthrown sides of the fault blocks (blue).

\section{Conclusions}

Seismic data interpretation is a primary method of viewing and mapping subsurface geologic features, making interpretation of structure and stratigraphy possible away from well control. One of the greatest strengths of 3D seismic is the dense, regular sampling of data over the regions of interest, providing images that accurately represent the areal extent of the structural features. The fundamental seismic data type is amplitude data, but seismic attributes (generated from amplitude) can reveal characteristics not easily seen in amplitude data itself. This paper aims to aid in developing understandings of 3D interpretation techniques. Integrating different types of attributes is particularly important to better structural mapping. It is possible to analyze both the picked horizons and the seismic trace data themselves to look for lateral discontinuity. When seismic amplitude changes associated with the features of interest are not noticeable on vertical sections, horizontal time or horizon slices extremely yield distinctive patterns that are clearly recognizable. Among the various seismic attributes available for characterizing complex geological structures (faults, folds, and channels), $3 \mathrm{D}$ coherence and curvature attributes have proven to be useful. Volumetric coherence and curvature attributes have been used for the detection of complex geological structures in the Shushan Basin (Egypt) and Arkoma Basin (USA).

Both coherence and curvature attributes can detect faults and channels in Shushan Basin (Egypt). Coherence attribute can be calculated over relatively long time window to create very precise images of faults in plan view. When used in this fashion, it becomes a detailed qualitative indicator of faults and their position. This allows interpreters to pick them quickly without anguishing over the precise position as they may do when using amplitude data alone. Volumetric curvature attributes indicate a better focusing of the folds features as compared with amplitude and coherence. Curvature attributes produce qualitative measures of folds in Arkoma Basin (USA) and are typically calculated over the interval of a single wavelet. Curvature attributes are more likely to usefully indicate regions of folding or subseismic faulting. The use of both coherence and curvature attributes for detailed structural interpretation illuminates different features of faults, folding, and stratigraphic features. Corendering volumetric curvature with coherence provides a particularly powerful tool and greatly aid 3D seismic interpretation by providing an accurate perspective of subsurface complex structure features (faults, folds, and channels).

\section{Conflict of Interests}

The authors declare that there is no conflict of interests regarding the publication of this paper.

\section{Acknowledgments}

The authors wish to express their gratitude to the Egyptian General Petroleum Corporation (EGPC) and Badr Petroleum Company (BAPETCO), Cairo, Egypt, for their approval and permission to use the material for study. They like also to thank the CGG Veritas and PABLO ENERGY II, LLC, USA, for providing the Arkoma Basin seismic data. They thank Schlumberger for furnishing the Petrel software for the seismic attributes analysis. They thank the editor and the anonymous reviewers for their constructive comments and suggestions which helped them to improve the paper.

\section{References}

[1] J. C. Dolson, M. V. Shann, S. Matbouly, C. Harwood, R. Rashed, and H. Hammouda, "The petroleum potential of Egypt," AAPG Memoir, vol. 74, pp. 453-482, 2001.

[2] W. Meshref, "Tectonic framework of global tectonics," in The Geology of Egypt, R. Said, Ed., pp. 439-449, A.A. Balkema, Rotterdam, The Netherlands, 1990.

[3] S. Moussa, "Evolution of the sedimentary basins of north western desert of Egypt," in Proceedings of the EGPC 8th Petroleum Exploration and Production Conference, pp. 1-22, Cairo, Egypt, 1986.

[4] E. C. Sullivan, K. J. Marfurt, A. Lacazette, and M. Ammerman, "Application of new seismic attributes to collapse chimneys in the Fort Worth Basin," Geophysics, vol. 71, no. 4, pp. B111-B119, 2006.

[5] O. O. Elebiju, G. R. Keller, and K. J. Marfurt, "Investigation of links between precambrian basement structure and paleozoic strata in the Fort Worth basin, Texas, U.S.A., using highresolution aeromagnetic (HRAM) data and seismic attributes," Geophysics, vol. 75, no. 4, pp. B157-B168, 2010.

[6] P. Sims, R. Saltus, and E. Anderson, "Preliminary Precambrian basement structure map of the continental United State-an interpretation of geologic and aeromagnetic data," United States Geological Survey Open-File Report 2005-1029, 2005.

[7] A. Sircar, "Hydrocarbon production from fractured basement formations," Current Science, vol. 87, no. 2, pp. 147-151, 2004.

[8] G. Keller, "Some thoughts on the structure and evolution of the Ouachita Mountains-Arkoma basin region," Oklahoma Geology Notes, vol. 69, pp. 4-12, 2009.

[9] M. Abdel Halim and M. Moussad, "Western desert oil and gas fields (a comprehensive overview)," in Proceedings of the 11th Petroleum Exploration and Production Conference (EPGC '92), p. 432, Egyptian General Petroleum Corporation, Cairo, Egypt, 1992.

[10] N. Suneson, "Structural interpretations of the Arkoma BasinOuachita Mountains transition zone, Southeastern Oklahoma," Circular-Oklahoma Geological Survey, vol. 97, pp. 259-263, 1995. 
[11] P. R. May, "The Eastern Mediterranean Mesozoic basin: evolution and oil habitat," American Association of Petroleum Geologists Bulletin, vol. 75, no. 7, pp. 1215-1232, 1991.

[12] A. Hegazy, "Western Desert oil and gas fields (a comprehensive overview)," in Proceedings of the 11th Petroleum Exploration and Production Conference (EGPC '92), Cairo, Egypt, 1992.

[13] J. Dolson, M. Shann, and R. Rashed, "The petroleum potential of Egypt," in Proceedings of the 2nd Wallace E. Pratt Memorial Conference "Petroleum Provinces of the 21st Century", p. 37, San Diego, Calif, USA, 2000.

[14] M. Younes and M. Bek, "Alamein basin hydrocarbon potentials, northern Western Desert, Egypt," in Proceedings of the AAPG Annual Convention, pp. 11-14, Salt Lake City, Utah, USA, 2003.

[15] M. Ayyad and M. Darwish, "Syrian Arc structures, a unifying model of inverted basins and hydrocarbon occurrences in North Egypt," in Proceedings of the 13th Petroleum Exploration and Production Conference (EGPC '96), pp. 40-59, Cairo, Egypt, 1996.

[16] G. Hantar, "North western desert," in The Geology of Egypt, R. Said, Ed., pp. 293-319, AA Balkema, Rotterdam, The Netherlands, 1990.

[17] N. Sultan and M. Halim, "Tectonic framework of Northern Western Desert, Egypt and its effect on hydrocarbon accumulations," in Proceedings of the EGPC 9th Petroleum Exploration and Production Conference, pp. 1-19, Cairo, Egypt, 1988.

[18] R. Guiraud, "Mesozoic rifting and basin inversion along the northern African Tethyan margin: an overview," Geological Society of London, vol. 132, no. 1, pp. 217-229, 1998.

[19] I. M. Hussein and A. M. A. Abd-Allah, "Tectonic evolution of the northeastern part of the African continental margin, Egypt," Journal of African Earth Sciences, vol. 33, no. 1, pp. 49-68, 2001.

[20] A. Shata, "New light on the structural development of the western desert of Egypt," Bulletin of Institute Desert, Egypt, vol. 6, pp. 117-157, 1953.

[21] A. Shata, "Structural development of the Sinai Peninsula, Egypt," Bulletin of the Institute of Desert of Egypt, vol. 6, no. 2, pp. 117-157, 1956.

[22] M. I. Youssef, "Structural pattern of Egypt and its interpretation," AAPG Bulletin, vol. 52, no. 4, pp. 601-614, 1968.

[23] E. M. El Shazly, "The geology of the Egyptian region," in The Ocean Basins and Margins, pp. 379-444, Springer, New York, NY, USA, 1978.

[24] G. Sestini, "Tectonic and sedimentary history of the NE African margin (Egypt-Libya)," Geological Society, vol. 17, pp. 161-175, 1984.

[25] J. Arbenz, "Structural framework of the Ouachita Mountains," in Stratigraphic and Structural Evolution of the Ouachita Mountains and Arkoma Basin, Southeastern Oklahoma and West-Central Arkansas: Applications to Petroleum Exploration, N. Suneson, Ed., vol.112A, pp. 1-40, Oklahoma Geological Survey, 2008.

[26] G. R. Keller, E. G. Lidiak, W. J. Hinze, and L. W. Braile, “The role of rifting in the tectonic development of the midcontinent, U.S.A," Tectonophysics, vol. 94, no. 1-4, pp. 391-412, 1983.

[27] G. Randy Keller and R. A. Stephenson, "The southern oklahoma and dniepr-donets aulacogens: a comparative analysis," Memoir of the Geological Society of America, vol. 200, pp. 127-143, 2007.

[28] W. A. Thomas, "Evolution of Appalachian-Ouachita salients and recesses from reentrants and promontories in the continental margin," American Journal of Science, vol. 277, no. 10, pp. 1233-1278, 1977.
[29] C. L. Liner, Elements of 3D Seismology, PennWell Books, Tulsa, Okla, USA, 2nd edition, 2004.

[30] S. Chopra and K. J. Marfurt, "Seismic attributes-a historical perspective," Geophysics, vol. 70, no. 5, article 3SO, 2005.

[31] S. Chopra and K. Marfurt, "Seismic attributes-a promising aid for geolo gic prediction," Canadian Society of Exploration Geophysicists (CSEG) Recorder, vol. 31, pp. 110-120, 2006.

[32] M. E. Sigismondi and J. C. Soldo, "Curvature attributes and seismic interpretation: case studies from Argentina basins," The Leading Edge, vol. 22, no. 11, pp. 1122-1126, 2003.

[33] M. Bahorich and S. Farmer, "3-D seismic discontinuity for faults and stratigraphic features: the coherence cube," The Leading Edge, vol. 14, no. 10, pp. 1053-1058, 1995.

[34] S. Chopra, "Coherence cube and beyond," First Break, vol. 20, no. 1, pp. 27-33, 2002.

[35] K. J. Marfurt, R. L. Kirlin, S. L. Farmer, and M. S. Bahorich, "3-D seismic attributes using a semblance-based coherency algorithm," Geophysics, vol. 63, no. 4, pp. 1150-1165, 1998.

[36] M. Bahorich and S. Farmer, "Method of seismic signal processing and exploration,” U.S. Patent no. 5,563,949, October 1996.

[37] K. J. Marfurt, V. Sudhaker, A. Gersztenkorn, K. D. Crawford, and S. E. Nissen, "Coherency calculations in the presence of structural dip," Geophysics, vol. 64, no. 1, pp. 104-111, 1999.

[38] A. Gersztenkorn and K. J. Marfurt, "Eigenstructure-based coherence computations as an aid to 3-D structural and stratigraphic mapping," Geophysics, vol. 64, no. 5, pp. 1468-1479, 1999.

[39] S. Stewart and R. Podolski, "Curvature analysis of gridded geological surfaces," Geological Society, vol. 127, no. 1, pp. 133-147, 1998.

[40] A. Roberts, "Curvature attributes and their application to 3D interpreted horizons," First Break, vol. 19, no. 2, pp. 85-100, 2001.

[41] S. Al-Dossary and K. J. Marfurt, "3D volumetric multispectral estimates of reflector curvature and rotation," Geophysics, vol. 71, no. 5, pp. P41-P51, 2006.

[42] S. Chopra and K. J. Marfurt, "Emerging and future trends in seismic attributes," Leading Edge, vol. 27, no. 3, pp. 298-318, 2008.

[43] K. Rektorys, "Differential geometry," in Survey of Applicable Mathematics, chapter 9, pp. 298-373, MIT Press, Cambridge, Mass, USA; Iliffe Books, London, UK, 1969.

[44] S. Chopra and K. J. Marfurt, "Volumetric curvature attributes add value to $3 \mathrm{D}$ seismic data interpretation," The Leading Edge, vol. 26, no. 7, pp. 856-867, 2007.

[45] S. Chopra and K. J. Marfurt, "Integration of coherence and volumetric curvature images," The Leading Edge, vol. 29, no. 9, pp. 1092-1107, 2010.

[46] A. Barnes, "Is curvature overrated?" First Break, vol. 32, no. 6, pp. 65-69, 2014.

[47] S. Chopra and K. J. Marfurt, "Detecting stratigraphie features via crossplotting of seismic discontinuity attributes and their volume visualization," Leading Edge, vol. 28, no. 12, pp. 14221426, 2009. 

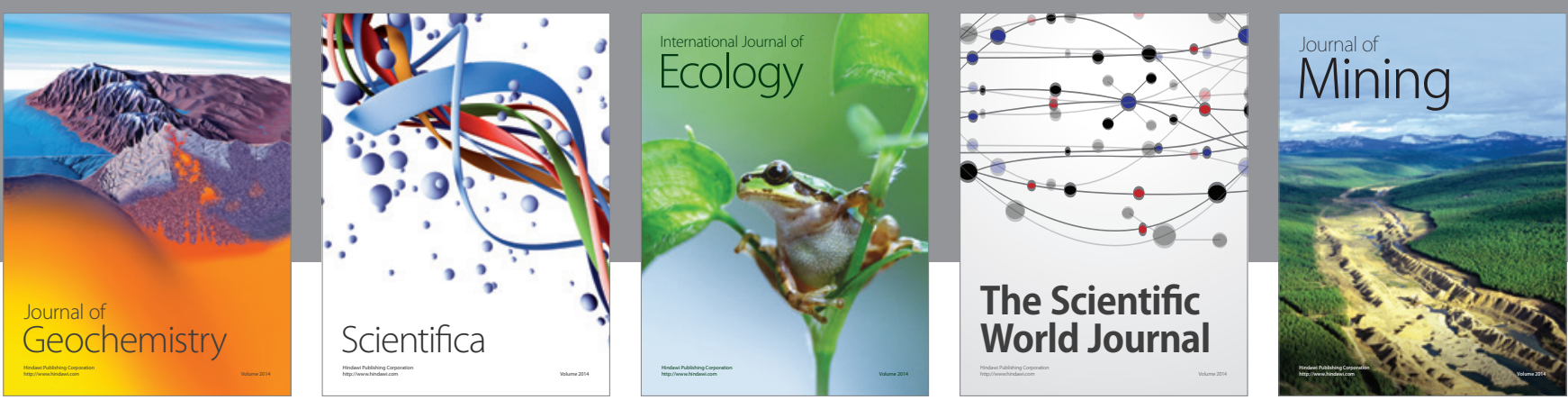

The Scientific World Journal
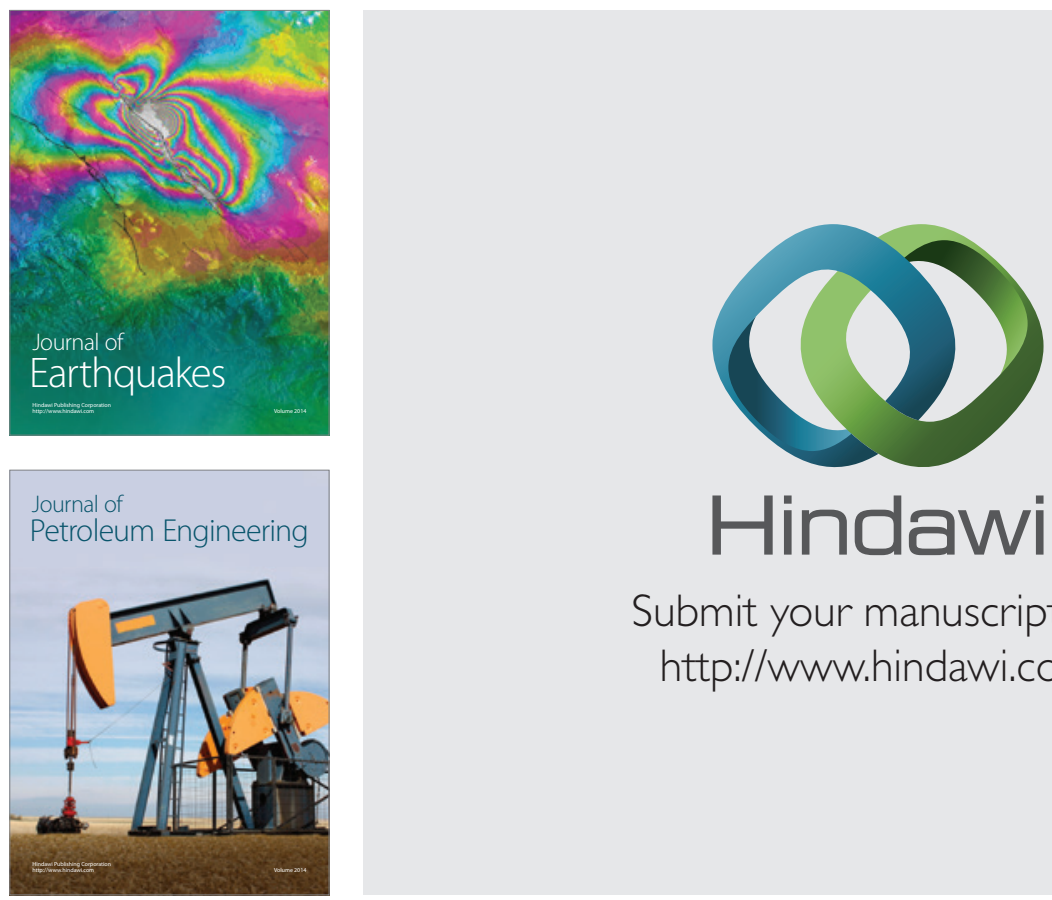

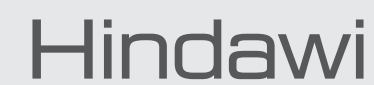

Submit your manuscripts at

http://www.hindawi.com
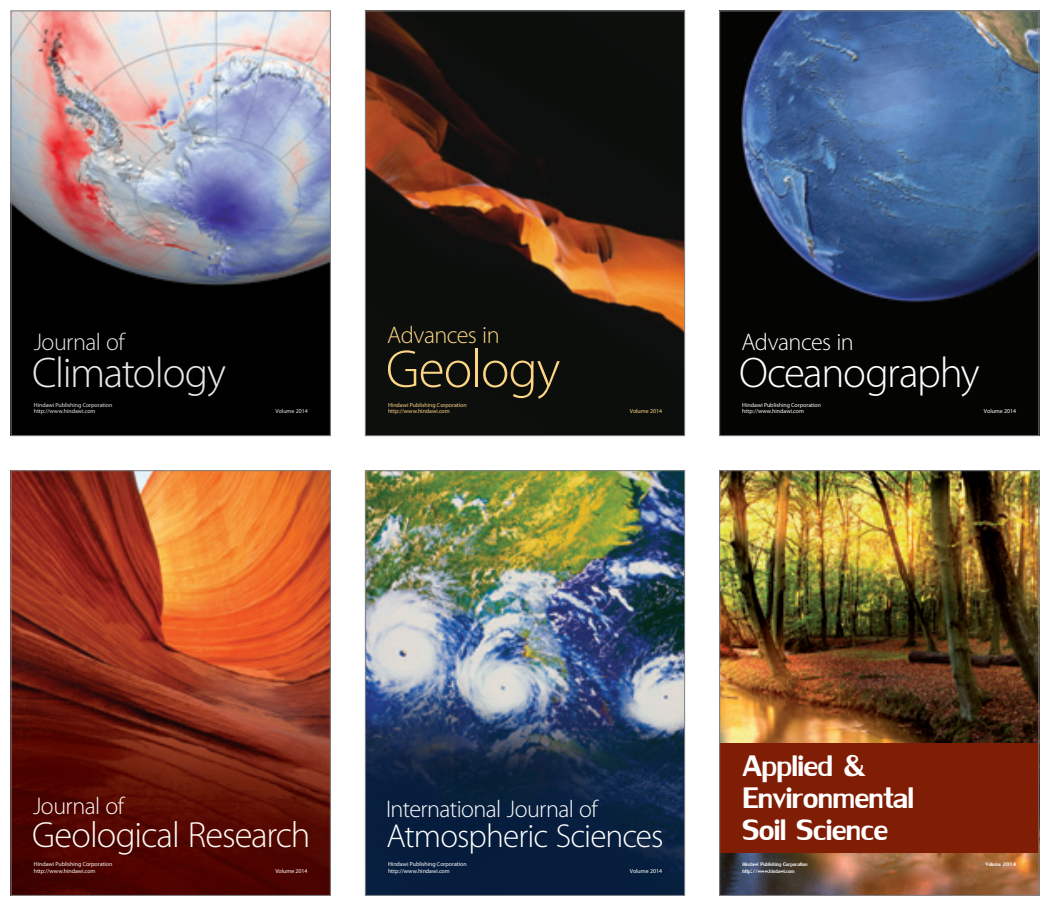
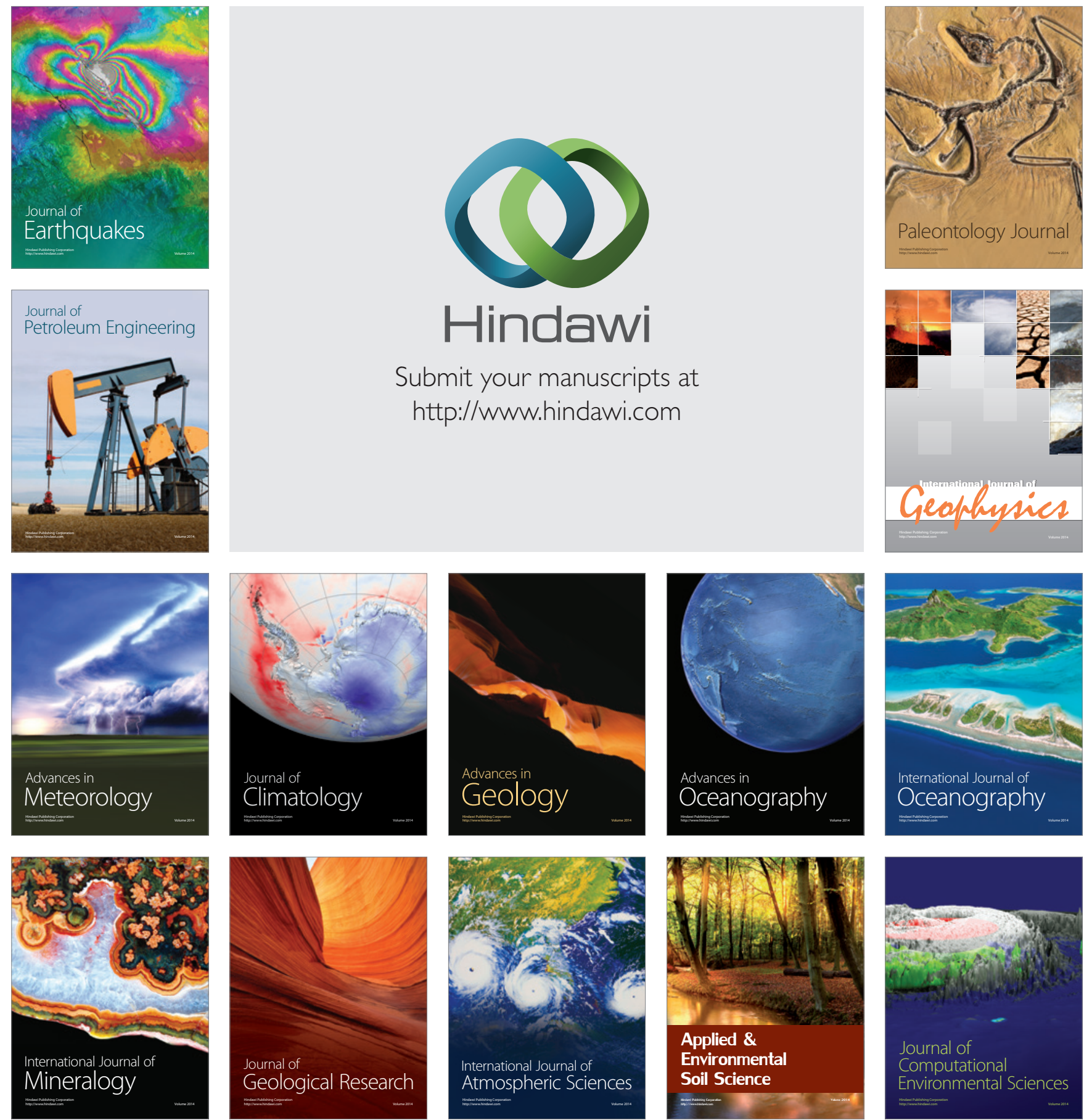